\title{
EDITORIAL
}

\section{Periódicos de Terapia Ocupacional e o desafio da inserção nas bases de dados internacionais}

Bases de dados conceitualmente abrangem uma coleção de dados ou de informaçóes disponíveis para um sistema computadorizado (BARSOTTI, 1990). Elas podem ser também definidas como uma coleção de itens sobre os quais podem ser realizadas buscas com o objetivo de se conhecer sobre um determinado assunto (LANCASTER, 1993).

O desenvolvimento de sistemas de informação e de bases de dados acompanha o surgimento da ciência da informação. Nascida em 1962, em uma reunião do Georgia Institute of Technology, foi conceituada como uma ciência que investiga as propriedades e o comportamento da informação, as forças que governam o seu fluxo, bem como os seus meios de processamento para acessibilidade e usabilidade ótimas. Inclui os processos de geração, disseminação, coleta, organização, armazenamento, recuperação, interpretação e uso da informação (SHERA; CLEVELAND, 1977; BRAGA, 1995).

O conhecimento sobre ciência da informação e o universo de ferramentas de informação existentes é pouco familiar aos terapeutas ocupacionais. Com o aumento do desenvolvimento da pesquisa no Brasil, esses profissionais, em especial os editores de revistas, passam a se aproximar desse conhecimento a fim de qualificar seus periódicos com o propósito de indexação nas bases de dados internacionais.

No mundo, existem atualmente pelo menos trinta títulos de periódicos de terapia ocupacional. Esse número pode não ser exato pela inexistência de um catálogo eletrônico que organize as coleçôes existentes para essa área do conhecimento. Carece também a informação sobre em quais bases de dados se encontram indexados os periódicos de terapia ocupacional, o que requer a investigação e a organização dessa informação para os terapeutas ocupacionais, com a finalidade de se conhecer em quais fontes de informação têm-se difundido o conhecimento produzido na área.

Há um esforço de alguns países na organização da informação sobre pesquisa em terapia ocupacional em fontes eletrônicas. São exemplos a Austrália, com a OT CATS, que abarca resumos de evidências em torno de questóes clínicas da prática, sendo uma versão menos rigorosa de revisóes sistemáticas (OCCUPATIONAL..., 2014). Ainda nesse país a base de dados OT Sekker foi criada a partir da ideia de 65 terapeutas ocupacionais que se reuniram em março de 2001 em Brisbane, Queensland para o Simpósio Internacional de Prática Baseada em Evidência em Terapia Ocupacional. Essa base contém resumos de revisóes sistemáticas e ensaios clínicos randomizados e controlados (OT SEEKER, 2014).

No Canadá, a OTDBASE criada em 1970 oferece um serviço de busca em uma lista de mais de vinte periódicos de terapia ocupacional, que contém mais de 10.000 resumos (OTDBASE, 2014). No Reino Unido, o site eletrônico OT Direct trata de uma produção independente organizada por terapeutas ocupacionais e disponibiliza informaçôes sobre bases de dados e outros sites (OT DIRECT, 2014). 
O desafio para inserçáo de periódicos de terapia ocupacional nas bases de dados internacionais relevantes para a área exige que as revistas existentes passem por constantes adequaçóes para atender aos critérios de indexação muitas vezes diferentes. Alguns critérios comuns para a avaliação dos periódicos são a disponibilizaçáo do texto completo em site eletrônico, a periodicidade regular, site bilíngue, resumos na língua inglesa, citaçóes contidas no texto e referências ao final. A inserção das revistas nas bases de dados permite a disseminação da informação, e no caso das bases internacionais, maior divulgação do periódico na comunidade internacional. Esperamos que esse processo auxilie na ampliaçáo do conhecimento produzido na área e, consequentemente, alimente o desenvolvimento da área.

Além dessa tarefa é também fundamental a inserção dos periódicos de terapia ocupacional em portais, bibliotecas eletrônicas, como mais uma forma de ampliar a divulgação dessas revistas em âmbito mundial, possibilitando o acesso à informação e a divulgação do conhecimento produzido pelos pesquisadores dessa área. A presente edição dos Cadernos de Terapia Ocupacional registra a inserção desse periódico na base de dados bibliográfica CUIDEN $^{\circledR}$ (España) e na PERIÓDICA (México), um índice de revistas latinoamericanas em Ciências, ampliando o rol de bases que compomos e reafirmando nosso trabalho de ampliação da disseminação do conhecimento em terapia ocupacional.

\section{Daniel Marinho Cezar da Cruz}

Departamento de Terapia Ocupacional, Universidade Federal de São Carlos - UFSCar

Jane Veiga

Faculdade de Biblioteconomia, Universidade Federal do Pará - UFPA

\section{Referências}

BARSOTTI, R. A informática na biblioteconomia e documentação. São Paulo: Polis, 1990.

BRAGA, G. M. Informação, ciência da informação: breves reflexóes em três tempos. Ciência da Informação, Brasília, v. 12, n. 1, p. 1-8, 1995.

LANCASTER, F. M. Indexação e resumos: teoria e prática. Brasília: Briquet de Lemos/Livros, 1993.

OCCUPATIONAL THERAPY CRITICALLY APPRAISED TOPIC - OT CATS. Australia. Disponível em: <http://www.otcats.com/>. Acesso em: 28 jul. 2014.
OT DIRECT. Pride Park. Disponível em: <http://www. otdirect.co.uk/>. Acesso em: 14 jul. 2014.

OT SEEKER. Brisbane. Disponível em: <http://www. otseeker.com/>. Acesso em: 20 jul. 2014.

OTDBASE. Canadá. Disponível em: <http://www. otdbase.org/>. Acesso em: 28 jul. 2014.

SHERA, J. H.; CLEVELAND, D. B. History and foundations of Information Science. Annual Review of Information Science and Technology, White Plains, v. 12 , p. $248-275,1977$. 